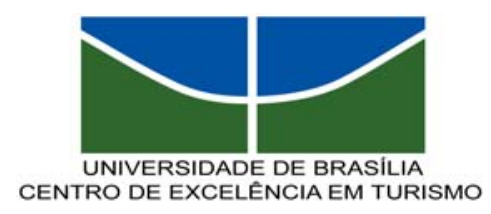

Universidade de Brasília

Centro de Excelência em Turismo

\title{
RISCOS OFERECIDOS À SAÚDE DOS TRABALHADORES DE UMA UNIDADE EM ALIMENTAÇÃO E NUTRIÇÃO (UAN)
}

Mariana Marques Nepomuceno

Monografia apresentada ao Centro de Excelência em Turismo da Universidade de Brasília como requisito parcial para a obtenção do certificado de Especialista em Qualidade em Alimentos

Orientação: Raquel Botelho

Brasília, DF, abril 2004 


\author{
UNIVERSIDADE DE BRASÍLIA \\ Centro de Excelência em Turismo \\ Curso de Especialização em Qualidade em Alimentos
}

\title{
RISCOS OFERECIDOS À SAÚDE DOS TRABALHADORES EM UMA UNIDADE DE ALIMENTAÇÃO E NUTRIÇÃO (UAN)
}

Mariana Marques Nepomuceno

Banca examinadora,
Raquel Botelho,Mestre Orientadora

Wilma Araújo, Doutor

Membro da Banca

Brasília, DF, abril 2004 
Mariana Marques Nepomuceno

Riscos oferecidos à saúde dos trabalhadores em uma Unidade de Alimentação e Nutrição (UAN)

Comissão Avaliadora

Raquel Botelho

Professora Orientadora

Brasília, DF, 23 abril 2004 


\section{DEDICATÓRIA}

Dedico este trabalho a minha tia, Sarah, pela confiança e incentivo dedicado por toda a vida, para que eu sempre lute e batalhe por todos os meus sonhos.

Agradeço em especial, ao meu noivo, Marcel, pela força que deu para que eu nunca desista de lutar por tudo que desejo, e pela paciência que teve comigo nos momentos difíceis. 


\section{AGRADECIMENTOS}

Agradeço a minha orientadora, Raquel Assunção Botelho, pelos ensinamentos, ajuda e paciência durante a elaboração do trabalho.

Aos amigos de pós-graduação, em especial à Marilena, que tanto me socorreu e ajudou nos momentos de indecisão.

Aos meus irmãos que tanto me deram força e coragem, mesmo de longe, para prosseguir em todas as etapas de minha vida. 


\section{EPÍGRAFE}

"A maior recompensa do nosso trabalho não é o que nos pagam por ele, mas aquilo em que ele nos transforma."

(John Ruskin) 


\section{RESUMO}

As Unidades de Alimentação e Nutrição (UANs) são ambientes de trabalho que oferecem uma série de riscos ocupacionais, devido à natureza das atividades desenvolvidas. Em virtude destes riscos a que estão expostos os funcionários podem apresentar problemas de saúde, ou ainda sofrerem acidentes de trabalho. Esse estudo teve por objetivos descrever e avaliar os riscos ambientais presentes na rotina de uma UAN em Brasília, Distrito Federal. Tais riscos foram avaliados utilizando uma ficha de observação (instrumento de avaliação). Dos dados obtidos, em relação aos riscos pode-se observar que os funcionários são expostos diariamente a uma série de riscos, provenientes de agentes ambientais mecânicos, químicos, biológicos e toxicológicos, e levam à conclusão de que estes fatores de riscos ambientais aliados a falta de medidas preventivas pode gerar acidentes de trabalho e/ou doenças profissionais.

Palavras-chaves: acidente de trabalho; riscos ambientais; agentes ambientais; saúde ocupacional e Unidade de Alimentação e Nutrição (UAN). 


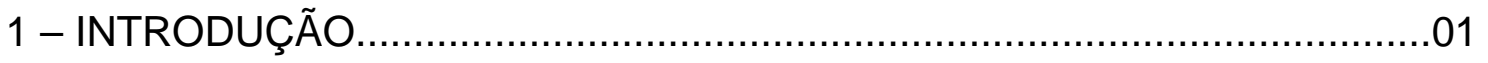

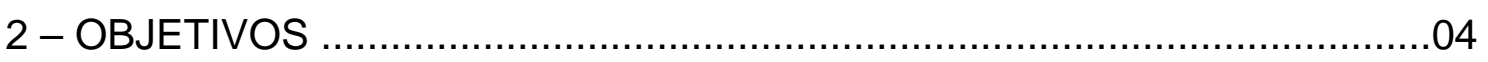

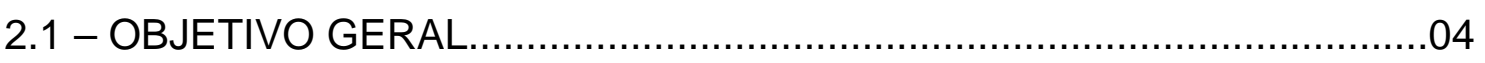

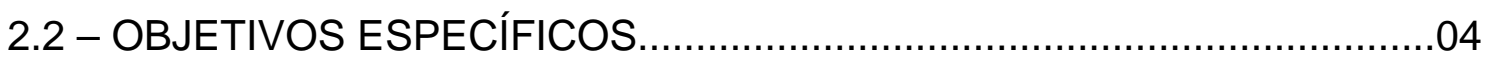

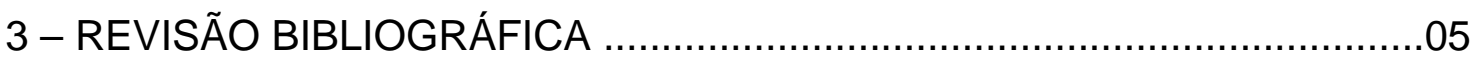

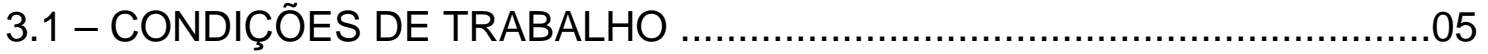

3.2 - CONDIÇÕES DE TRABALHO EM UMA UNIDADE DE ALIMENTAÇÃO E

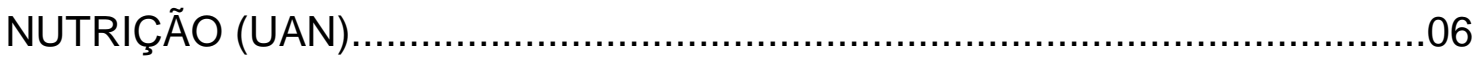

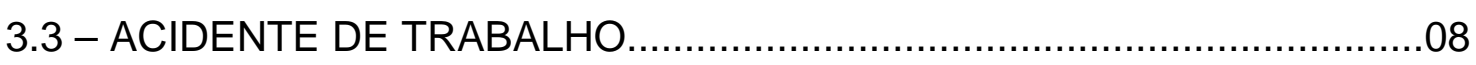

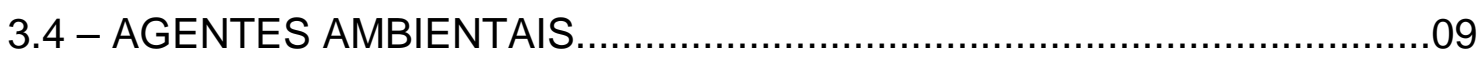

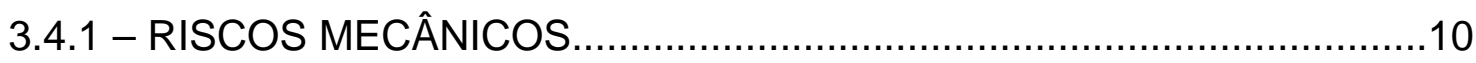

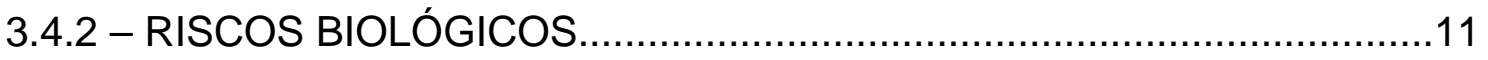

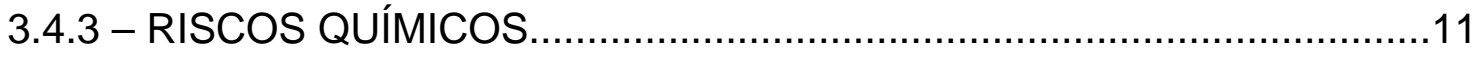

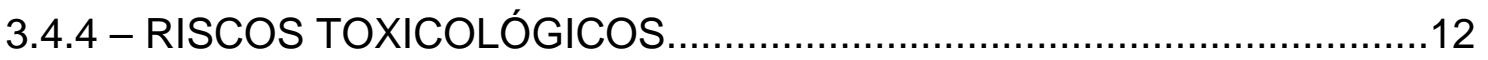

3.4.4.1 - HIDROCARBONETOS POLÍCICLICOS AROMATICOS (HPA)

3.5 - NORMATIZAÇÃO/NORMALIZAÇÃO DA EXPOSIÇÃO AO RISCO.........16

3.6 - MEDIDAS DE PREVENÇÃO DOS RISCOS AMBIENTAIS.......................16

3.6.1 - EQUIPAMENTOS DE PROTEÇÃO COLETIVA (EPC`S).....................16

3.6.2 - EQUIPAMENTOS DE PROTEÇÃO INDIVIDUAL (EPI`s)....................17

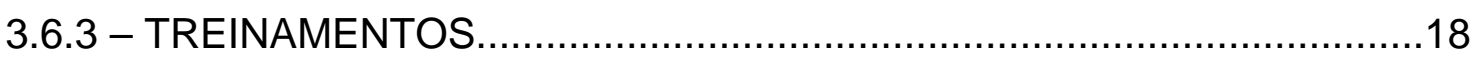

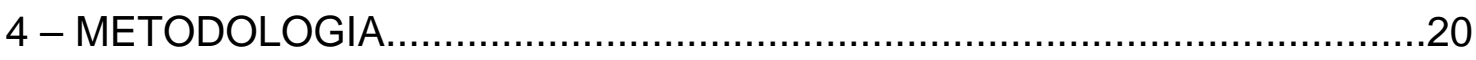

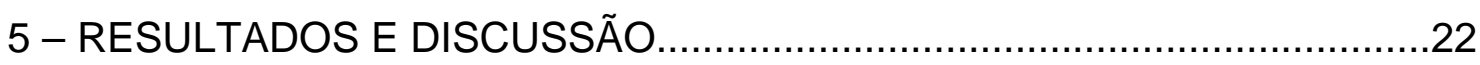

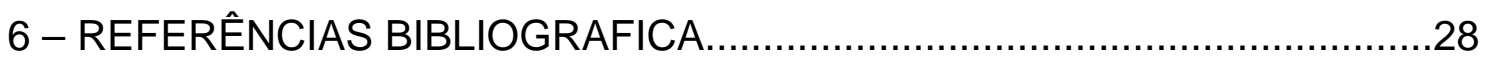

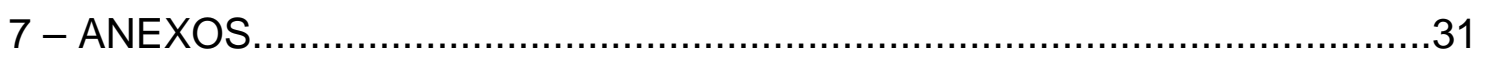




\section{I - INTRODUÇÃO}

Funcionário é "aquele que tem ocupação permanente retribuída; empregado", conforme descrito por Ferreira (1975). O funcionário ou empregado presta serviços de natureza não eventual ao empregador ou empresa da qual faz parte. (BRASIL, 2003).

A empresa assume os riscos da atividade econômica; admite, assalaria e dirige a prestação pessoal de serviço, objetivando atingir interesses comuns com maior eficiência (BRASIL, 2003; TEIXEIRA, 2003).

Atualmente, os movimentos trabalhistas reivindicam melhores condições de trabalho, com a finalidade de garantir o bem-estar físico e social dos trabalhadores (TEIXEIRA, 2003).

Wisner, citado em Matos (2000), definiu que as condições de trabalho de uma forma tradicional e ampla englobam tudo que influencia o próprio trabalho: o posto de trabalho, o ambiente, a duração da jornada de trabalho, o horário, a alimentação, o transporte, a relação produção-salário e o serviço médico.

O desenvolvimento de um bom trabalho não depende apenas do empregador, mas também do trabalhador, cabendo às empresas cumprir e fazer cumprir as normas de segurança e de medicina do trabalho (anexo 1) e ainda instruir os empregados quanto às precauções que devem ser adotadas no sentido de evitar acidentes de trabalho ou doenças ocupacionais. Simultaneamente, os empregados devem observar e colaborar com a empresa na aplicação das normas de segurança e de medicina do trabalho. (BRASIL, 2003).

A Saúde Ocupacional, ou Medicina do Trabalho, como conhecida anteriormente, é uma especialidade que avalia os riscos existentes em cada posto de trabalho nas empresas, e cuida para que os trabalhadores não tenham sua saúde ameaçada ou prejudicada pela função que exercem, melhorando suas condições de trabalho e de vida (PEREIRA, 2001). 
O Ministério do Trabalho, órgão responsável pela fiscalização dos ambientes de trabalho no Brasil (VASCONCELOS, 1997), por meio da Norma Regulamentadora 7 (NR - 7) obriga todas as empresas e instituições que admitam trabalhadores, à elaboração e implementação do Programa de Controle Médico de Saúde Ocupacional (PCMSO), que tem o objetivo de promover e preservar a saúde dos trabalhadores (PEREIRA, 2001).

O PCMSO é um conjunto de medidas com caráter preventivo, que visa especialmente os riscos ambientais a que os funcionários estejam expostos, e que possam influenciar a relação saúde/função. O programa é desenvolvido de maneira articulada com as outras NR's, em especial a NR - 9 que trata da Prevenção de Riscos Ambientais. Os fatores ambientais compreendem todas as influências externas que se fazem sentir sobre o indivíduo, como a condição social, a ocupação, os hábitos alimentares, o estilo de vida, a exposição a agentes físicos e químicos (CARNEIRO et. al. 1997).

Segundo Vasconcelos (1997), as intervenções em Saúde do Trabalhador pretendem adequar o planejamento das ações, estabelecendo uma nova relação dinâmica entre investigações epidemiológicas e as intervenções sanitárias, visando à transformação dos processos de trabalho, determinantes do adoecimento dos trabalhadores.

Dentre as várias possibilidades de riscos, verificam-se que as exposições excessivas e contínuas dos indivíduos a vários compostos químicos são os maiores obstáculos para uma avaliação epidemiológica das doenças advindas do ambiente. (TOLEDO, 2002). Muitos compostos químicos apresentam diferentes graus de toxicidade, bem como diferenças quanto ao metabolismo (PIVETTA, 2001). É de grande importância o risco de contaminação humana por estes compostos químicos em virtude de suas propriedades físico-químicas e da grande distribuição ambiental (NETTO, 2000).

Entende-se por risco a probabilidade de ocorrência de um efeito adverso, durante um certo período de tempo, como resultado de uma determinada exposição. Os 
riscos que são extrínsecos ao indivíduo são denominados de fatores ambientais e compreendem a condição social, a ocupação, os hábitos alimentares, o estilo de vida, a exposição a agentes físicos e químicos (CARNEIRO, 1997).

Uma U.A.N. desempenha atividades relacionadas à alimentação e nutrição (OLIVEIRA, 2000) para coletividades, melhor definindo, as unidades de alimentação trabalham com produção e distribuição de alimentos (MATOS, 2000).

Em uma U.A.N., devido às atividades realizadas, os funcionários estão sujeitos a apresentarem problemas de saúde devido aos agentes ambientais ao qual estão expostos diariamente (MATOS, 2000).

A literatura é escassa na verificação sobre os riscos a que estão submetidos os funcionários que exercem tais atividades. Desta forma, verificou-se a importância de avaliar o risco ocupacional dos trabalhadores de uma Unidade de Alimentação e Nutrição e os seus efeitos sobre a saúde do trabalhador. 


\section{II - OBJETIVOS}

\section{2 - OBJETIVOS}

\section{1- Objetivo geral:}

Avaliar os riscos à saúde dos funcionários devido às condições de trabalho em uma Unidade de Alimentação e Nutrição (U.A.N.) do Distrito Federal.

\section{2- Objetivos específicos:}

Avaliar os riscos toxicológicos a que estão submetidos os funcionários em uma Unidade de Alimentação e Nutrição.

> Avaliar os riscos químicos a que estão submetidos os funcionários em uma U.A.N.

> Avaliar os riscos biológicos aos quais estão submetidos os funcionários de uma U.A.N. estão expostos.

> Avaliar os riscos mecânicos aos quais estão submetidos os funcionários estão sujeitos em uma U.A.N. 


\section{III - REVISÃO BIBLIOGRÁFICA}

\section{1 - CONDIÇÕES DE TRABALHO}

A sociedade brasileira convive com um alto índice de mortalidade e morbidade por acidentes de trabalho, problema este que traz danos irreparáveis à saúde dos trabalhadores. Por ano, a mortalidade por acidente de trabalho atinge valores em torno de 20 mortes por 100 mil trabalhadores segurados pela previdência social (PROGRAMA TRABALHADOR SEGURO, 2003). Em 1997, cerca de 400.000 trabalhadores sofreram acidentes e doenças relacionados ao trabalho.

Conforme os registros feitos nos últimos cinco anos, a incidência de acidentes de trabalho estabilizaram em níveis inaceitáveis, sendo a maioria das vítimas jovens e adultos com menos de 40 anos de idade. As condições inadequadas dos ambientes e processos de trabalho geram fatores de risco que comprometem a saúde dos trabalhadores (BRASIL, 2003).

A Secretaria de Segurança e Saúde no Trabalho (SSST), órgão de âmbito nacional competente para coordenar, orientar, controlar e supervisionar atividades relacionadas com a segurança e medicina do trabalho (NR-1) enfrenta inúmeros problemas: sistema de estatísticas de acidentes e doenças relacionadas ao trabalho deficiente e impreciso, dificuldades e resistências quanto à formação de parcerias efetivas com outros órgãos setoriais e com a sociedade no desenvolvimento de ações voltadas para a prevenção dos acidentes e de doenças relacionadas ao trabalho; dificuldades de abordar o setor informal da economia seja pela limitação dos instrumentos formais de fiscalização do trabalho, seja pela invisibilidade do setor nos 
sistemas de informações existentes; baixo volume de estudos e pesquisas realizados sobre a realidade brasileira em segurança e saúde no trabalho, associado a insuficiente divulgação.

Estes problemas dificultam a busca para a melhoria das condições de trabalho e para a redução dos índices de agravos à saúde decorrentes do trabalho. Com isso, o trabalho educativo nas empresas, divulgando informações sobre formas de prevenção de acidentes e doenças causadas pelo trabalho, são de grande importância.

A interação do homem com seu ambiente de trabalho torna-se prejudicial à saúde, se os riscos de trabalho ultrapassarem sua tolerância; ou benéfica, quando seu trabalho é inteiramente adaptado aos fatores humanos, físicos e psicológicos (MATOS, 2000).

\section{2 - CONDIÇÕES DE TRABALHO EM UMA UNIDADE DE ALIMENTAÇÃO E NUTRIÇÃO (UAN)}

Uma UAN tem o objetivo de servir refeições saudáveis do ponto de vista nutricional e segura do ponto de vista higiênico-sanitária, além de praticar custos adequados e otimizados (TOMASIAK, 2004), mas são ambientes de trabalho que oferecem uma série de riscos ocupacionais (ABREU, 2002).

Segundo MONTEIRO, citado em MATOS (2000), o trabalho em UANs é caracterizado por movimentos repetitivos, levantamento de peso excessivo e permanência em pé por períodos prolongados. Além disso, com a finalidade de atender a demanda, os funcionários da UAN, durante a produção, sofrem pressão temporária para se ajustarem aos horários de distribuição das refeições.

Uma máquina pode manter o mesmo ritmo de produção, porém, ao longo do tempo há um desgaste de seus componentes, em geral, substituíveis. Com o homem o mesmo não acontece (ABREU, 2002).

O trabalho acelerado em uma UAN, freqüentemente realizado em condições desfavoráveis, é resultado de um mau planejamento do espaço físico (MONTE, 2003). 
A falta de planejamento adequado, a falta de treinamento de pessoal, o uso de equipamentos ultrapassados, somados ao excesso de atividades contribuem para o agravamento ou ocasionam problemas à saúde do trabalhador, podendo causar acidentes de trabalho (TOSTES, 2003).

A exigência por uma alta produtividade em curto tempo, aliada a condições de trabalho inadequadas, com problemas de ambiente, equipamentos e processos, acabam promovendo uma redução na produtividade, e um aumento no número de problemas de saúde e de acidentes de trabalho (MATOS, 2000).

Em virtude destas características, para muitos operadores, o trabalho na produção de alimentos é visto como provisório; estimativas baseadas em experiências afirmam que somente $10 \%$ destes operadores que entram no setor fazem carreira (MATOS, 2000).

O desenvolvimento de um bom trabalho, não depende apenas do trabalhador, dos equipamentos e das áreas para a realização das tarefas. Dependem também de uma organização adequada e de fatores sociais que possam gerar a satisfação do operador em seu ambiente de trabalho.

Melhorar as condições de trabalho produz impacto positivo na a produtividade e na qualidade dos serviços e produtos; considerando que as condições de trabalho se encontram relacionadas à saúde do trabalhador.

Como citado anteriormente, nos artigos 157 e 158 da Consolidação de Leis Trabalhistas - CLT (BRASIL, 2003) são estabelecidas às competências das empresas e as atribuições dos trabalhadores, referentes à prevenção a acidentes de trabalho.

As empresas são obrigadas a manter serviços especializados em segurança e medicina do trabalho, de acordo com as normas expedidas pelo Ministério do Trabalho, artigo 162 da CLT (Anexo 2).

As Normas Regulamentadoras - NR, relativas à segurança e medicina do trabalho são obrigatórias às empresas, sejam elas privadas ou públicas. A prática das NR's não desobriga as empresas do cumprimento de outras disposições (Anexo 3). 


\section{3 - ACIDENTE DE TRABALHO}

PIZA (1997), citado em TORRES (2003), define que acidente de trabalho é qualquer fator ou acontecimento, que ocorre no exercício do trabalho a serviço da empresa ou pelo exercício do trabalho de segurados, provocando lesão corporal como cortes, queimaduras e outros, ou perturbação funcional que cause a morte ou a perda ou ainda redução permanente ou temporária da capacidade para o trabalho. Inclui nesses casos também a chamada doença profissional.

Existem evidências de que medidas de segurança inadequadas e a falta de treinamento dos funcionários aumentam os riscos de acidentes de trabalho, no setor de alimentação coletiva, especialmente, nos horários de ritmo de trabalho acelerado (MATOS, 2000).

No Brasil, a notificação dos acidentes de trabalho limita-se a pouco mais de um quarto do total de trabalhadores (CONCEIÇÃO et. al., 2001). São um importante problema de saúde pública. O Instituto Nacional de Seguridade Social (INSS) registrou, no ano de 1991, 640.790 acidentes de trabalho entre os 22.792.858 segurados. Em 1997, o número de acidentes de trabalho registrados diminuiu para 369.605 segurados (LIMA, 2000).

Os acidentes de trabalho são ocorrências relevantes dentre as causas externas atendidas em serviços de saúde. Estudo realizado no Rio de Janeiro por DESLANDES (1999), em dois hospitais municipais de emergência, mostrou que a proporção de acidentes de trabalho, dentre as causas externas, foi de 18,7\% num hospital e de $15 \%$ no outro (CONCEIÇÃO et. al., 2001).

Outro estudo realizado, no período de 1988 a 1989, constatou que aproximadamente $50 \%$ dos acidentes de trabalho ocorreram em cozinhas, e que as queimaduras e lesões osteomusculares são as principais causas de acidentes (MATOS, 2000).

Os funcionários de uma UAN estão sujeitos a acidentes de trabalho decorrentes de agentes ambientais presentes na rotina das unidades, cabendo ao 
empregador informar os empregados sobre os procedimentos que deverão ser adotados na empresa para evitar tais acidentes. Deve também informar quais as medidas que devem ser tomadas caso ocorra algum acidente de trabalho ou profissional.

Para evitar os acidentes de trabalho na produção de alimentos, é importante aplicar treinamentos referentes à Segurança no Trabalho, buscando com isso conscientizar e capacitar os funcionários para que possam reconhecer as possibilidades de risco e assim atuar como colaboradores para a segurança do ambiente.

\section{4 - AGENTES AMBIENTAIS}

Agentes ambientais ou riscos ambientais são substancias nocivas específicas encontradas nos ambientes de trabalho, tendo papéis centrais na causa das doenças profissionais, quando encontradas acima dos limites de tolerância. (VASCONCELOS, 1995).

Segundo LAURELL (1981), citado em VASCONCELOS (1995), a própria categoria trabalho é tratada pela Medicina do Trabalho com um problema ambiental, uma vez que põe os trabalhadores em contato com agentes químicos, mecânicos, biológicos ou toxicológicos que causam acidentes ou enfermidades.

Ao conceituar doença como um processo apenas biológico, a Medicina do Trabalho busca sempre agentes biológicos causais capazes de desencadear processos biológicos. Com isso, as doenças do trabalho são consideradas como desvios ou fatos inevitáveis no processo técnico de trabalho (VASCONCELOS, 1995).

Os riscos ambientais se subdividem em riscos químicos, físicos, microbiológicos e ergonômicos.

$\Rightarrow$ Físicos: frio, umidade, calor e ruídos;

$\Rightarrow$ Químicos: decorrentes da utilização de produtos de limpeza em geral: 
$\Rightarrow$ Ergonômicos: decorrentes de espaços e dimensões mal definidos, prejudicando a funcionalidade operacional, causando incompatibilidade entre os trabalhadores e seu trabalho, podendo causar desconforto, fadiga e, conseqüentemente, lesões;

$\Rightarrow$ Microbiológicos: decorrentes da capacidade dos organismos vivos de causarem doenças no organismo.

Os riscos ambientais acima estão presentes nas unidades de produção, porém ao realizar um mapeamento estes riscos, verifica-se que os toxicológicos e os mecânicos merecem relevância:

$\Rightarrow$ Toxicológicos: decorrentes de substâncias tóxicas, provenientes da fumaça produzida durante o preparo dos alimentos (cozidos, assados, fritos e grelhados);

$\Rightarrow$ Mecânicos: decorrentes de atividades que envolvem máquinas e equipamentos que podem eventualmente causar acidentes de trabalho.

\subsection{1 - Riscos mecânicos}

De acordo com TOSTES (2003), riscos mecânicos são os que têm origem nas atividades que envolvem máquinas e equipamentos, responsáveis pelo surgimento de lesões nos trabalhadores decorrentes de acidente de trabalho.

Máquinas desreguladas, equipamentos em proteção ou defeituosos, entre outras, são exemplos de agentes que oferecem riscos ao trabalhador podendo resultar em acidente.

O Ministério do Trabalho é responsável pelo estabelecimento de medidas preventivas contra acidentes, o que inclui o uso de equipamentos de proteção individual (BRASIL, 2003).

Em uma UAN os riscos mecânicos que geram acidentes freqüentemente, envolvem cortes de membros superiores com objetos cortantes (facas, moedores de carne, etc.), choque elétrico em fios mal encapados, acidentes causado devido ao uso 
de equipamentos defeituosos ou estragados, e acidentes devido à falta do uso de Equipamentos de Proteção Individual (EPI).

\subsection{2 - Riscos biológicos}

Os riscos biológicos relacionam-se à capacidade de organismos vivos, como bactérias, fungos, helmintos, protozoários e vírus, entre outros patogênicos, causarem doenças no organismo humano (TOSTES, 2003).

Os exemplos de agentes biológicos mais comuns são: animais mortos, insetos, água, lixo urbano, materiais contaminados, exsudatos de animais e humanos, pessoas portadoras de doenças infecto-contagiosas, entre outras. Para o homem as principais vias de contaminação são a cutânea, a gastrointestinal e a via respiratória (PIVETTA \& HUET, 2001).

Em uma Unidade de Alimentação e Nutrição os funcionários estão expostos aos microrganismos provenientes de resíduos de alimentos, durante a manipulação dos mesmos e ao manipular o lixo orgânico resultante da produção de alimentos.

Medidas preventivas como manter os locais de trabalho limpos, armazenamento adequado dos alimentos e manejo adequado do lixo, ajudam a controlar a contaminação por microrganismos.

\subsection{3 - Riscos químicos}

No Brasil, em 1983, o Ministério do Trabalho editou a primeira portaria que definia indicadores biológicos de exposição para 29 agentes químicos em ambientes de trabalho. Os valores estabelecidos nessa portaria e nas subseqüentes não são baseados em estudos nacionais, mas adotados de outros países, principalmente dos Estados Unidos. Atualmente, está estabelecido na legislação brasileira, Quadro I da Norma Regulamentadora NR-7 (Brasil, 1999), indicadores biológicos para 26 agentes químicos. 
Os riscos químicos são oferecidos por substâncias, compostos ou produtos químicos que possam penetrar no organismo pela via respiratória ou ser absorvidos através da pele ou por ingestão (TOSTES, 2003). Os riscos dependem do agente químico e da natureza da atividade de exposição.

Os produtos químicos utilizados em UAN são produtos para higiene pessoal, ambiental, de utensílios e equipamentos. São produtos que têm soda caustica detergentes, desinfetantes, como tal, requerem cuidados específicos ao serem manipulados.

É de grande importância seguir as informações e recomendações contidas nos rótulos das embalagens dos produtos químicos para evitar e prevenir acidentes decorrentes do uso incorreto destas substancias.

O uso de Equipamentos de Proteção Individual (EPI’s) como óculos com armação de borracha e vedação completa, máscara facial filtro, luvas de borracha e botas de borracha auxiliam na proteção contra a contaminação, evitando que entrem em contato com o organismo dos funcionários ao manipular os produtos (FUNDACENTRO, 1993),

\subsection{4 - Riscos toxicológicos}

Toxicidade é o caráter do que tem a propriedade de envenenar (FERREIRA, 1975). Tóxico se refere à presença de agentes estranhos aos alimentos que, quando em concentrações elevadas, podem levar ao aparecimento de efeitos danosos a saúde das pessoas a ele expostos (MÍDIO \& MARTINS, 2000).

Modernamente conceitua-se a toxicidade de uma substância como a medida relativa do risco que ela apresenta de produzir um efeito tóxico no sistema biológico exposto. Toxicidade não é potencial, mas sim real e pode ser determinada quantitativamente (MÍDIO \& MARTINS, 2000). 
A contribuição da toxicologia para a redução da incidência do câncer em geral se faz por intermédio da identificação de substâncias químicas (CARNEIRO et. al., 1997).

Em UANs, os agentes tóxicos a que os funcionários são expostos diariamente provêem da fumaça produzida durante o preparo dos alimentos, do aquecimento de óleos, dos churrascos (costelas de porco, steak, bife grelhado, entre outros), além da reação de produtos de limpeza que liberam vapores ou gases quando aplicados nas áreas ou equipamentos a serem higienizadas ou detetizadas.

Os hidrocarbonetos aromáticos (HPAs) e seus derivados, substâncias altamente carcinogênicas, a que estão associados ao aumento da incidência de diversos tipos de cânceres nos homens são exemplos de agentes tóxicos no ambiente de produção (NETTO et. al., 2000).

\subsubsection{Ocorrência dos Hidrocarbonetos Policíclicos Aromáticos (HPAs)}

Os Hidrocarbonetos Policíclicos Aromáticos (HPAs) são de grande importância, pois ocorrem como contaminantes em diferentes grupos de alimentos que são usados para elaboração dos cardápios. Incluem-se vegetais, frutas, carnes, óleos e gorduras, grãos, bebidas, alimentos grelhados, torrados e de origem marinha (CAMARGO \& TOLEDO, 2002).

A severidade dos efeitos da exposição aos HPAs sobre o organismo humano fez com que especial atenção fosse dedicada ao desenvolvimento de metodologias analíticas hábeis para identificação e determinação de bioindicadores da concentração absorvida (dose interna), da concentração presente nos sítios de ação biológica críticos (dose biológica efetiva) assim como de quaisquer efeitos precoces (NETTO et. al., 2000).

A exposição humana aos HPAs se dá principalmente através da contaminação ambiental. A tabela 1 apresenta os níveis de HPAs encontrados em amostras ambientais e biológicas. 
Tabela 1. Níveis de HPAs encontrados em amostras ambientais e biológicas (NETTO, 2000).

\begin{tabular}{cc}
\hline Tipo de amostra & Concentração \\
\hline Ar & 1,3 a $500 \mathrm{mg} / \mathrm{m} 3$ \\
Solo & $0,8 \mathrm{mg} / \mathrm{kg}-100 \mathrm{mg} / \mathrm{kg}$ \\
Água & 2,50 a $500 \mathrm{mg} / \mathrm{l}$ \\
Plantas & $<1,50 \mathrm{mg} / \mathrm{kg}$ \\
Alimentos & 0,1 a $20 \mathrm{mg} / \mathrm{kg}$ \\
\hline
\end{tabular}

De fato, devido ao caráter lipofílico, os Hpas e seus derivados podem ser absorvidos pela pele, por ingestão ou por inalação, sendo rapidamente distribuídos pelo organismo (NETTO et.al., 2000).

O benzo[a]pireno pertence à classe dos HPAs é encontrado nos alimentos (carnes e peixes) cozidos, defumados, assados e grelhados (MÍDIO \& MARTINS, 2000). Tem sido utilizado como indicador arbitrário do potencial carcinogênico de alimentos contaminados por HPAs (NOELL \& TOLEDO, 1997).

NOELL e TOLEDO (1997), citado em CAMARGO e TOLEDO (2002), relataram níveis médios de benzo [a] pireno de 16,41 e 0,1 microgramas por kilograma de peso, respectivamente, em churrasco de picanha assada com e sem gordura (considerando que a formação de HPAs é maior na presença de gordura na carne). A tabela 2, apresentada abaixo, mostra os níveis de benzo[a]pireno em produtos defumados, utilizados em unidades de alimentação. 
Tabela 2. Níveis de benzo [a] pireno em produtos defumados (NOELL \& TOLEDO, 1997).

\begin{tabular}{cc}
\hline Alimento & Benzo [a] pireno $(\mathrm{g} / \mathrm{kg})$ \\
\hline Carne (kundi) & $10,5-66,9$ \\
Chá & 5,8 \\
Bacon & 0,4 \\
Carne de porco & 2,50 \\
Lingüiça & 2,30 \\
Peito de peru & 0,10 \\
Frango & 0,20 \\
Queijo & 0,91 \\
Presunto & 0,0090 \\
salsicha & 0,32 \\
\hline
\end{tabular}

Contudo, os funcionários de uma UAN, que trabalham em ambientes diretamente influenciados por fontes de HPAs, estão submetidos a um risco maior de desenvolver câncer de pulmão ou outros tumores (NETTO et. al., 2000).

O potencial carcinogênico apresentado por alguns HPAs, entre eles o benzo[a]pireno, tem estimulado o desenvolvimento de pesquisas no sentido de identificar e quantificar as prováveis fontes de exposição humana a estes compostos (CAMARGO \& TOLEDO, 1996).

A elevada taxa de mortalidade relacionada ao câncer (cerca de 6,5 milhões de pessoas por ano) e o fato de que os tratamentos para estas doenças serem dispendiosos, demorados e normalmente trazerem muito sofrimento aos doentes, expõem claramente os benefícios potenciais que o entendimento, a avaliação e o controle da exposição humana a substâncias que possua atividade carcinogênica/mutagênica podem trazer, particularmente quando se sabe que a grande 
maioria dos cânceres resulta de interações genéticas e ambientais, sendo as causas externas (ambientais), em conjunção com fatores de suscetibilidade adquirida, as mais importantes. No caso dos HPAs e de seus derivados, isto é feito geralmente através do monitoramento dos níveis ambientais destas substâncias, do conhecimento das suas vias de penetração no organismo, de seu metabolismo, bem como da avaliação precoce de seus efeitos biológicos.

\section{5 - A NORMATIZAÇÃO/NORMALIZAÇÃO DA EXPOSIÇÃO AO RISCO}

Como inevitável à exposição aos agentes ambientais constituídos ou reunidos em uma empresa, para as UANs, a Medicina do trabalho recorre, dentre outras medidas, à fixação de normas que limitem parcialmente a exposição aos agentes ambientais (VASCONCELOS, 1995).

Os critérios de classificação de doenças profissionais têm variado em função de circunstâncias sociais e históricas, os "níveis admissíveis" de exposição modificamse enormemente de um para outro país, de uma para outra época. As normas de exposição ocupacional estão, em sua grande maioria, voltadas ao trabalho cujos principais fatores de risco são os agentes químicos (VASCONCELOS, 1995).

\section{6 - MEDIDAS DE PREVENÇÃO DOS RISCOS AMBIENTAIS}

A diminuição da exposição aos agentes ambientais presentes nas UANs envolve a adoção de Equipamentos de Proteção Coletiva (EPC`s) e de Equipamentos de Proteção Individual (EPI's) com o objetivo de neutralizar os riscos que comprometam a Segurança e a Saúde do Trabalhador (FUNDACENTRO, 1993).

Além, dos equipamentos de proteção coletivos e individuais, os treinamentos são de grande importância para a prevenção de acidentes, visto que, é realizado com o intuito de manter e disseminar a segurança da equipe. 


\subsection{1 - Equipamento de Proteção Coletiva (EPC`s)}

Os Equipamentos de Proteção Coletiva (EPC`s) são dispositivos utilizados no ambiente de trabalho para proteger os trabalhadores dos riscos inerentes aos processos (TORRES, 2003).

São equipamentos simples, que variam desde o corrimão de uma escada até equipamentos mais sofisticados como detectores de gases. Não geram desconforto aos funcionários, pois são instalados no ambiente e não nas pessoas.

Facilitam os processos das empresas, considerando que colaboram para o aumento da produtividade e minimizam os efeitos de perdas em função de melhorias no ambiente.

Os equipamentos de proteção coletiva não prejudicam a eficiência do trabalho, quando adequadamente escolhidos e instalados. Devem ser adequados aos riscos que irão neutralizar; devem depender unicamente da atuação do homem para atender suas finalidades; devem ser resistentes à agressividade de impactos, à corrosão, a desgastes; devem permitir a facilidade de limpeza, de lubrificação e de manutenção; devem criar outros tipos de riscos, principalmente mecânicos como obstrução de passagens e formação de cantos vivos (TORRES, 2003).

\subsection{2 - Equipamento de Proteção Individual (EPI`s)}

Os Equipamentos de Proteção Individual, usualmente identificados pela sigla "EPI's", formam, em conjunto, um recurso amplamente empregado para a segurança do trabalhador no exercício de suas funções. Têm grande responsabilidade na preservação da incolumidade do trabalhador contra diversos riscos oferecidos pelo ambiente de trabalho (FUNDACENTRO, 1993).

De acordo com a Consolidação de Leis Trabalhistas, os EPI's devem ser adotados sempre que os procedimentos operacionais não oferecerem completa proteção contra os riscos de acidentes e danos à saúde dos empregados. São 
complementares na neutralização dos riscos que comprometem a segurança e a saúde do trabalhador. Além disto, protegem contra qualquer elemento que possa ser nocivo ao trabalhador (FUNDACENTRO, 1993).

Em uma UAN, os EPI’s usados são: botas de borracha (para os membros inferiores); luvas de malha de aço e de flanela ou de feltro, óculos contra gases e vapores (para os membros superiores); aventais de borracha ou oleado - impermeável e casaco térmico (para o tronco).

Conforme especificado no Artigo 158 da CLT, parágrafo único cabe ao empregado o uso dos equipamentos de proteção individual fornecidos pela empresa, sendo responsabilizado por sua conservação (BRASIL, 2003).

As organizações são obrigadas a fornecer material de proteção de boa qualidade e confiabilidade, com a finalidade de garantir a integridade da saúde do trabalhador, fazendo as substituições quando necessário por equipamentos novos.

Os trabalhadores são encarregados de comunicar ao empregador quando ocorrer qualquer alteração com o equipamento de proteção individual que o torne impróprio ao uso (TORRES, 2003).

\subsection{3 - Treinamento}

Segundo BAPTISTA (1974), citado em TORRES (2003), o treinamento é um processo que pode desenvolver a aptidão no emprego de métodos seguros de trabalho e na aplicação de práticas seguras durante o desempenho das tarefas.

O treinamento deve ser desenvolvido e aplicado corretamente, com atividades práticas supervisionadas e com correção imediata, de forma a evitar erros e riscos. Tão importante quanto o treinamento é o treinamento de reciclagem, que tem a intenção de relembrar e fixar na memória a cultura dos hábitos de segurança.

Os "hábitos de segurança" sejam eles bons ou maus, podem ser interpretados como certo comportamento adquirido, como um padrão de ações realizadas de determinada maneira que respeite uma ordem lógica de realização. Uma vez adquirido 
um hábito para realizar uma tarefa ele se repetirá o tempo todo sem que se pare para pensar seus detalhes. Um hábito adquirido e praticado repetidamente se estabelece. Uma vez que esse hábito foi adquirido, praticado e enraizado é extremamente difícil mudá-lo. Quando se trata de bons hábitos isso é positivo, e negativo para os maus hábitos (TORRES, 2003).

A conscientização e a capacitação dos trabalhadores, para que possam reconhecer as possibilidades de riscos, propiciarão as condições mínimas necessárias para que possam colaborar ativamente na condução do gerenciamento do ambiente em que estão inseridos. 


\section{CAPÍTULO IV - METODOLOGIA}

Foi realizada uma pesquisa bibliográfica associada a uma pesquisa exploratória, estruturada, participante desenvolvida em uma Unidade de Alimentação e Nutrição (UAN), localizada na cidade de Brasília, no Distrito Federal, Brasil.

A pesquisa bibliográfica foi desenvolvida entre janeiro de 2004 e abril de 2004 , baseada em artigos e livros de bases indexadas que apresentam respaldo cientifico. A pesquisa exploratória foi desenvolvida no decorrer de uma semana, de 01 a 05 de dezembro de 2003.

Os riscos mecânicos compreenderam questões referentes ao estado dos equipamentos e das maquinas e as respectivas medidas preventivas. Para avaliar os riscos biológicos foram consideradas questões como o manuseio do lixo, afecções da pele dos funcionários e outras doenças e suas respectivas medidas de segurança.

Os riscos químicos oferecidos nas unidades foram avaliados durante a operação de limpeza, incluindo o uso de produtos de limpeza, e as medidas de segurança. O risco toxicológico foi avaliado por meio da avaliação dos sintomas físicos.

O instrumento foi aplicado através de observação direta de todos os funcionários que desenvolvem tarefas na produção de refeições tanto no turno matutino como no vespertino. Todos foram acompanhados durante uma semana para avaliar a periodicidade dos eventos detectados como de risco

A avaliação foi desenvolvida em uma semana, excluindo os sábados e domingos (que o restaurante não funciona) no período de 09 horas às 16 horas. Esse período foi estabelecido para realizar avaliação, pois corresponde ao horário de preparo e distribuição de alimentos e higienização do local de trabalho, utensílios e máquinas na unidade em questão. 


\section{1 - MATERIAIS}

A pesquisa foi conduzida em uma Unidade de Alimentação e Nutrição (UAN), localizada no Setor de Administração Federal Sul, cidade de Brasília, no Distrito Federal.

Foi desenvolvida no decorrer de uma semana (01 a 05 de dezembro de 2003) nos turnos matutino e vespertino (das 9 horas às 16 horas), operações referentes à preparação dos cardápios apresentados no anexo 3.

Esse período foi estabelecido para realizar a avaliação, pois corresponde ao horário de preparo e distribuição de alimentos e higienização do local de trabalho, utensílios e máquinas na unidade em questão.

\section{2 - MÉTODOS}

A avaliação dos riscos foi realizada a pari do uso de um instrumento de pesquisa, que compreendia os seguintes itens:

- Perfil dos funcionários ( anexo 4) - ver página 40

- Riscos mecânicos (anexo 5) - ver página 42

- Riscos biológicos (anex06) - ver página 44

- Riscos químicos (anexo 7) - ver página 45

- Riscos toxicológicos (anexo 8) - ver página 46

A adequação ou não aos procedimentos operacionais foram assinalados da seguinte forma: em caso de adequação (SIM); em caso de inadequação (NÃO).

Para o desenvolvimento da pesquisa exploratória, foi desenvolvido um instrumento de avaliação de riscos que os funcionários são expostos quando trabalham em UAN. Este foi baseado no roteiro de observação da ANVISA e nas NRs. 
Para a elaboração do instrumento foi considerado o risco ambiental a que os funcionários da UAN são expostos diariamente na pratica de suas atividades ou funções. Os riscos ambientais avaliados foram: os riscos mecânicos, os químicos, biológicos e os toxicológicos. 


\section{V - RESULTADOS E DISCUSSÃO}

A empresa pesquisada foi um restaurante do tipo self-service (alimentação coletiva), que presta serviços em um órgão público na cidade de Brasília, Distrito Federal.

A unidade funciona no período das 7 horas às 19 horas de segunda a sextafeira. Os funcionários têm jornada de trabalho de oito (8) horas diária, com descanso semanal de quarenta e oito (48) horas consecutivas. Ao público, o atendimento ocorre entre 8 horas e 19 horas.

A produção de alimentos tem início às 7 horas e às 14 horas e 30 minutos é finalizada. O horário de pico da produção ocorre entre 11 horas e 14 horas e 30 minutos. Após esse horário de pico, é realizada a higienização de máquinas, utensílios e de toda a área de produção.

Para o presente estudo participaram todos os funcionários (14) da empresa que trabalham na área de produção de alimentos, correspondendo a 37,83\% do total de 37 funcionários da empresa.

O grupo avaliado foi composto por $42,85 \%$ de mulheres e por $57,14 \%$ de homens. Este perfil contraria estimativas de março de 2004 da DATASUS, que identifica maior incidência do sexo feminino, com um número de 1.164.958 indivíduos $(52,15 \%)$, nos postos de trabalho; a população masculina ocupada é de 1.068.656. A faixa etária média do grupo é de 32 anos e o grau de escolaridade da maioria é de $1^{\circ} \mathrm{e}$ $2^{\circ}$ graus incompletos. A tabela 1 apresenta as características do grupo estudado. 
Tabela 1. Características do grupo estudado.

\begin{tabular}{|c|c|c|c|}
\hline Variáveis & $\begin{array}{l}\text { Homens } \\
\mathrm{N}=8\end{array}$ & $\begin{array}{c}\text { Mulheres } \\
\qquad \mathrm{N}=6\end{array}$ & $\begin{array}{c}\text { Grupo* } \\
N=14\end{array}$ \\
\hline Faixa etária (anos) & & & \\
\hline$-(\min .-\max )$. & $24-48$ & $25-38$ & $24-48$ \\
\hline Idade média & 32,75 & 30,16 & 31,64 \\
\hline Escolaridade: & & & \\
\hline $1^{\circ} \mathrm{grau}$ incompleto & 4 & 1 & 5 \\
\hline $1^{\circ}$ grau completo & 2 & 1 & 3 \\
\hline $2^{\circ}$ grau incompleto & 0 & 1 & 1 \\
\hline $2^{\circ}$ grau completo & 2 & 3 & 5 \\
\hline $\begin{array}{c}\text { Tempo de } \\
\text { empresa (inicio } \\
\text { da pesquisa) }\end{array}$ & 5 & 5 & 5 \\
\hline
\end{tabular}

- Grupo refere-se a homens e mulheres avaliados

A figura 1 mostra o percentual de funções realizadas pelos funcionários de unidade em questão. Os números 1, 2 e 3 apresentados no eixo $X$ da figura, representam o número de funções exercidas, enquanto no eixo das ordenadas verificase a relação percentual. 


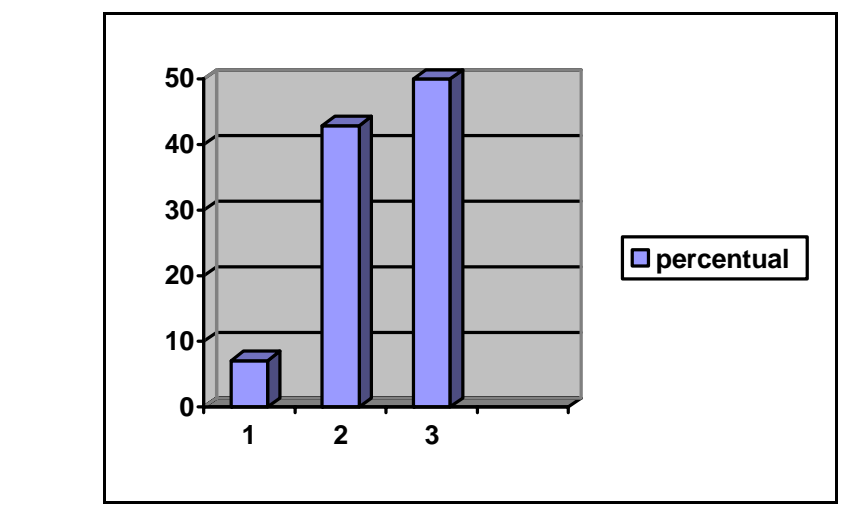

Figura 1. Percentual de funções exercidas pelos funcionários.

Do grupo estudado, verifica-se que 50\% desempenhavam alem da atividade para a qual foram contratados, mais duas atividades diferentes, 42,85\% desempenhavam no mínimo uma atividade extra e apenas 7,14\% desempenhavam somente a atividade para a qual foram contratados e qualificados.

Com o trabalho excessivo é comum a carga horária de trabalho ser superior às 40 horas semanais, o que pode se tornar prejudicial à produção/hora, como ainda trazer um aumento do absenteísmo, acompanhado de doenças e acidentes, conforme mostrado por TORRES (2003).

Estes dados indicam que a metade (50\%) dos funcionários da unidade, além de exercerem as atividades de sua qualificação também exerce ocupações para as quais não estão aptos, concordando assim com o estudo de Reis et. al. (1999).

Por exercerem mais de uma atividade este grupo tem maior possibilidade de sofrer acidentes de trabalho e de apresentarem problemas de saúde como, por exemplo, a fadiga (ocasionada pelo trabalho excessivo associado à falta de prática de atividades físicas), conforme apresentado por Metzner e Fischer (2001) em sua pesquisa.

A tabela 2 mostra os resultados obtidos por meio da aplicação de avaliação de riscos ambientais. Os dados mostram que $64,44 \%$ das alternativas para avaliar os riscos obtiveram resposta negativa, o que significa que os riscos ambientais não estão controlados. Com isso, aumenta-se a probabilidade dos funcionários desta unidade 
apresentarem agravamento ou problemas de saúde, e conseqüentemente, acidentes de trabalho.

Tabela 2. Avaliação dos riscos ambientais oferecidos na UAN.

\begin{tabular}{cccc}
\hline $\begin{array}{c}\text { Agentes } \\
\text { ambientais }\end{array}$ & $\begin{array}{c}\text { Afirmativo } \\
\text { (SIM) }\end{array}$ & $\begin{array}{c}\text { Negativo } \\
\text { (NÃO) }\end{array}$ & $\begin{array}{c}\text { Número de } \\
\text { alternativas }\end{array}$ \\
\hline Mecânicos & 7 & 8 & 15 \\
Biológicos & 1 & 6 & 7 \\
Químicos & 2 & 9 & 11 \\
Toxicológicos & 6 & 6 & 12 \\
TOTAL & $\mathbf{1 6}$ & $\mathbf{2 9}$ & $\mathbf{4 5}$ \\
\hline
\end{tabular}

Dentre os riscos ambientais a que os funcionários da UAN estão expostos, os mais prejudiciais à saúde são os biológicos $(85,71 \%)$ e os químicos $(81,88 \%)$. As questões que avaliam os riscos biológicos capazes de causar prejuízos à saúde dos funcionários abordam a disposição, acondicionamento e manipulação do lixo, o estado de saúde dos funcionários e limpeza da área de produção de alimentos. Conforme apresentados na tabela 2, os riscos biológicos oferecem alto risco aos trabalhadores, visto que, 85,71\% dos itens avaliados não atendem as normas da Portaria CVS - 6/99, de 10.03.99 da Vigilância Sanitária da Secretaria de Estado da Saúde e na Portaria SVS/MS no 326, de 30 de julho de 1997. As portarias em questão tratam de ações de controle sanitário na área de produção de alimentos.

Quanto aos riscos biológicos, este estudo evidenciou que os trabalhadores da unidade em questão trabalham expostos a um perigo constante, visto que, dos itens observados relacionados aos fatores que podem causar doenças no organismo humano $85,71 \%$ apresentam resposta desfavorável às medidas de controle e de prevenção para evitar a contaminação biológica. Pivetta e Huet (2001) em seu estudo mostram que alterações do estado de saúde do trabalhador e alguns parâmetros 
biológicos estão associados, e que as atividades de prevenção, são o principal meio para limitar as patologias que estão correlacionadas ao ambiente.

O segundo colocado considerando o critério de risco à saúde do trabalhador são os químicos, que tiveram $81,88 \%$ de respostas negativas nos itens avaliados, de acordo com as normas das portarias acima citadas. O uso de produtos de limpeza pelos funcionários não é realizado de forma segura como também, não são aprovados e adequados para o uso em UAN`s. O que confere aos funcionários da unidade um alto risco a saúde.

Quanto aos fatores de risco químico, os dados obtidos mostram que o risco de contaminação é alto. No estudo foram investigadas a qualidade e adequação dos produtos utilizados para higienização e desinfecção dos utensílios e equipamentos e da área de trabalho, que apresentaram impróprios para higienizar e desinfetar os utensílios e equipamentos da área de trabalho, pois são recomendados para outros fins como, por exemplo, o sabão em pó utilizado para lavar o chão é recomendado para lavar roupas não obtendo como resultado final uma limpeza adequado (remoção de gorduras sobre o piso, por exemplo). O uso de produtos químicos inadequados pode resultar em resíduos dos mesmos nos utensílios ou um desgaste maior seja do chão e dos equipamentos e utensílios em que são usados. Os produtos não são autorizados pelo Ministério da Saúde, e quando usados podem causar irritação da pele, irritação da mucosa ocular, entre outros sintomas, causando danos à saúde do trabalhador.

Dentre as questões que tratam dos depósitos e instalações de inflamáveis e dos sistemas de combate e prevenção contra o $\mathrm{fogo}_{2}$ os riscos de acidentes diminuem significativamente, pois seguem as recomendações do Código de Segurança contra incêndio e pânico (lei no 12.111) do Corpo de Bombeiros.

No que se refere aos utensílios e máquinas, estes não tem manutenção preventiva e se encontram em funcionamento precário e estão sujeitos a panes, oferecendo riscos aos trabalhadores que os manipulam. Os riscos mecânicos que apresentaram respostas negativas foram os relacionados ao uso de equipamentos de proteção individual, sendo evidente que medidas de segurança inadequadas aumentam 
os riscos de acidentes de trabalho, no setor de alimentação, o que é confirmado no estudo de MATOS (2000).

Os riscos toxicológicos estão presentes durante toda a produção de alimentos e diariamente. Observando as preparações do cardápio (anexo 9) e considerando o risco toxicológico oferecido por diferentes grupos de alimentos, a produção de fumaça durante o preparo de alimentos grelhados, assados e frituras podemos confirmar que funcionários estão altamente expostos à contaminação. Os dados observados mostram que o risco oferecido pela exposição aos agentes tóxicos, em especial os HPAs, poderia ser evitado com medidas preventivas simples como, a troca do óleo utilizado nas frituras diariamente e evitando que o óleo quando utilizado se aquece além do necessário produzindo fumaça (atingindo o ponto de saturação), que é tóxica tanto para quem consome quanto para quem trabalha produzindo o alimento. Os funcionários da unidade trabalham em um ambiente que é diretamente influenciado por fontes de HPAs devido à produção de carnes grelhadas em chapa produzidas diariamente, o que confere a eles um risco maior de desenvolver doenças como o câncer decorrente desta substância, que tem alto potencial carcinogênico.

Nenhuma prevenção é tomada no que se refere à contaminação tóxica, o que aumenta a incidência de problemas causados a saúde dos trabalhadores inclusive o aumento de incidência de câncer, como mostrado por Carneiro et. al (1997) em seu estudo.

Em todos os itens avaliados no presente estudo, o maior problema observado é a falta do uso de Equipamentos de Proteção Individual que poderiam ajudar a prevenir os acidentes de trabalho, além da falta de treinamento dos trabalhadores da unidade, que tem o objetivo de conscientizar os funcionários das causas de riscos e suas medidas preventivas.

Para garantir a segurança no trabalho é de grande importância à conscientização e a capacitação dos funcionários associado à conscientização do empregador para que se possa prevenir e evitar os riscos ambientais presentes no ambiente de trabalho. 


\section{VI - REFERÊNCIAS BIBLIOGRÁFICAS}

- ABREU, E.S. et. al. Fatores de Risco Ambiental para Trabalhadores de uma Unidade de Alimentação e Nutrição (UAN). Nutrição em Pauta, São Paulo, 2003.

- BRASIL. CLT Acadêmica (2003). Consolidação das Leis Trabalhistas: decreto-lei N.5.452 de 1 de maio de 1943. Com colaboração do texto: Antonio Luiz de Toledo Pinto, et. al. $1^{\mathrm{a}}$ ed. São Paulo: Saraiva, 2003

- CAMARGO, M.C.R; TOLEDO, M.C.F. Hidrocarbonetos policíclicos aromáticos: uma revisão. Bol. SBCTA, Campinas, 36(1): pág. 69-78, janeiro/junho, 2002.

- CARNEIRO, M.R.G. et. al. Fatores de risco ambientais para o câncer gástrico: a visão do toxicologista. Caderno de Saúde Pública, Rio de Janeiro, vol.13, supl. 1, janeiro, 1997.

- CONCEIÇÃO, P.S.A. et. al. Acidentes de trabalho atendidos em serviço de emergência. Centro de Estudos da Saúde do Trabalhador. Bahia, 2000.

- FERREIRA, A.B.H. Novo Dicionário da Língua Portuguesa. 1ª ed. Rio de Janeiro: Nova Fronteira S.A., 1975.

- FUNDACENTRO. Fundação Jorge Duprat Figueiredo de Segurança e Medicina do Trabalho. Equipamentos de Proteção Individual. 1ªed. São Paulo, 1993.

- LIMA, R.C. et. al. Percepção de exposição a cargas de trabalho e riscos de acidentes em Pelotas, RS (Brasil). Caderno de Saúde Pública, São Paulo, vol.33, n.2, abril, 1999.

- MATOS, C.H. Condições de Trabalho e Estado Nutricional de Operadores do Setor de Alimentação Coletiva: Estudo de Caso. Florianópolis, 2000. $148 f$. Dissertação (Mestrado em Engenharia de Produção) - Programa de Pós-graduação em Engenharia de Produção/Ergonomia, Universidade Federal de Santa Catarina.

- METZNER, R.J., FISCHER, M.F. Fadiga e capacidade para o trabalho em turnos fixos de doze horas. Revista Saúde Pública, São Paulo, vol. 35, n.6, dez. 2001. 
- MIDIO, A.F.; MARTINS, D.I. Toxicologia de Alimentos. $1^{\mathrm{a}}$ ed. São Paulo: Livraria Varela, 2000.

- MONTE, C.R.V. et. al. Aplicação de um modelo para avaliar projetos de Unidades de Alimentação e Nutrição. Nutrição Brasil. São Paulo, v.3, n.1, p; 11-17, janeiro/fevereiro, 2004.

- MONTEIRO, M.S.; GOMES, J.R. Reestruturação produtiva e saúde do trabalhador: um estudo de caso. Caderno de Saúde Pública, Rio de Janeiro, 2000.

- NETTO, A.D.P. et.al. Avaliação da contaminação humana por hidrocarbonetos policíclicos aromáticos (HPAs) e seus derivados nitratos (NHPAS): uma revisão metodológica. Química Nova, São Paulo, vol. 23, n.6, dezembro, 2000.

- NOELL, I.S.; TOLEDO, M.C.F. Benzo[a]pireno em carnes defumadas pelos processos caseiro e industrial. Revista Brasileira de Toxicologia, 1997.

- PEREIRA, E.M.S. Programa de Controle Médico de Saúde Ocupacional. In: Centro Universitário do Triângulo Mineiro - UNIT. Administração de Serviços Alimentares. Uberlândia, 2001. n.1.

- PIVETTA, F., HUET, J.M. Monitoramento biológico: conceitos e aplicações em Saúde Pública. Caderno de Saúde Pública, Rio de Janeiro, vol. 17, n.3, maio/junho 2001.

- PROGRAMA TRABALHO SEGURO. www.fundacentro.gov.br, 16 de março de 2004.

- TEIXEIRA, S.M.F.G. Administração Aplicada às Unidades de Alimentação e Nutrição. $1^{\mathrm{a}}$ ed. São Paulo: Editora Atheneu, 2003.

- TORRES, M.G.V. Segurança no Trabalho em Unidades de Alimentação e Nutrição - Treinamentos e Dinâmicas. Brasília, 2003. Universidade de Brasília.

- TRANCOSO, S.C.; TOMASIAK, F.S. Estrutura de uma Unidade de Alimentação e Nutrição. Nutrição Brasil. São Paulo, v.3, n.1, p. 18-21, janeiro/fevereiro, 2004.

- VASCONCELOS, F.D. Uma crítica do uso de Padrões de Exposição na Vigilância da Saúde do Trabalhador. Caderno de Saúde Pública, Rio de janeiro, vol.11, n.6, outubro/dezembro, 1995. 
- VASCONCELOS, L.C.F. Investigação epidemiológica e intervenção sanitária em saúde do trabalhador: o planejamento segundo bases operacionais. Caderno de Saúde Pública, Rio de Janeiro, vol.13, n.2, abril/junho, 1997. 


\section{ANEXO 1 \\ CAPÍTULO V \\ DA SEGURANÇA E DA MEDICINA DO TRABALHO}

Seção I

Disposições Gerais

Art. 157. Cabe às empresas:

I - cumprir e fazer cumprir as normas de segurança e medicina do trabalho;

II - instruir os empregados, através de ordens de serviço, quanto às precauções a tomar no sentido de evitar acidentes do trabalho ou doenças ocupacionais;

III - adotar as medidas que lhe sejam determinadas pelo órgão regional competente;

IV - facilitar o exercício da fiscalização pela autoridade competente.

- Redação dada pela Lei n. 6.514, de 22-12-1977.

Art. 158. Cabe aos empregados:

I - observar as normas de segurança e medicina do trabalho, inclusive as instruções de que trata o item II do artigo anterior;

II - colaborar com a empresa na aplicação dos dispositivos deste Capítulo.

- Caput com redação dada pela Lei n. 6.514, de 22-12-1977.

Parágrafo único. Constitui ato faltoso do empregado a recusa injustificada: 
a) À observância das instruções expedidas pelo empregador na forma do item II do artigo anterior;

b) b) ao uso dos equipamentos de proteção individual fornecidos pela empresa.

- Parágrafo com redação dada pela Lei n. 6.514, de 22-12-1977.

- Vide Enunciada 289 do TST.

Art. 159. Mediante convênio autorizado pelo Ministério do Trabalho, poderão ser delegadas a outros órgãos federais, estaduais ou municipais atribuições de fiscalização ou orientação às empresas quanto ao cumprimento das disposições constantes deste Capítulo.

- Redação dada pela Lei n. 6.514, de 22-12-1977. 


\title{
ANEXO 2
}

\author{
Seção III \\ Dos Órgãos de Segurança e de Medicina \\ do Trabalho nas Empresas
}

\begin{abstract}
Art. 162. As empresas, de acordo com normas a serem expedidas pelo Ministério do Trabalho, estarão obrigadas a manter serviços especializados em segurança e em medicina do trabalho.
\end{abstract}

- Caput com redação dada pela Lei n. 6.514, de 22-12-1977.

Parágrafo único. As normas a que se refere este artigo estabelecerão:

a) classificação das empresas segundo o número mínimo de empregados e a natureza do risco de suas atividades;

b) o número mínimo de profissionais especializados exigidos de cada empresa, segundo o grupo em que se classifique, na forma da alínea anterior;

c) a qualificação exigida para os profissionais em questão e o seu regime de trabalho;

d) as demais características e atribuições dos serviços especializados em segurança e em medicina do trabalho, nas empresas.

- Parágrafo único com redação dada pela Lei n. 6.514, de 22-12-1977. 


\begin{abstract}
ANEXO 3
Normas regulamentadoras de Segurança e Saúde do Trabalho

Considerações Gerais
\end{abstract}

1.1. As Normas Regulamentadoras - NR, relativas à segurança e medicina do trabalho, são de observância obrigatória pelas empresas privadas e pelos órgãos públicos da administração direta e indireta, bem com pelos órgãos dos Poderes Legislativo e Judiciário, que possuam empregados regidos pela Consolidação das Leis do Trabalho CLT.

1.1.1. As disposições contidas nas Normas Regulamentadoras - NR aplicam-se, no que couber, aos trabalhadores avulsos, às entidades ou empresas que thes tomem o serviço e aos sindicatos representativos das respectivas categorias profissionais.

1.2. A observância das Normas Regulamentadoras - NR não desobriga as empresas do cumprimento de outras disposições que, com relação à matéria, sejam incluídas em códigos de obras ou regulamentos sanitários dos estados ou municípios, e outras, oriundas de convenções e acordos coletivos de trabalho.

1.3. A Secretária de Segurança e Saúde no Trabalho - SSST é o órgão de âmbito nacional competente para coordenar, orientar, controlar e supervisionar as atividades relacionadas com a segurança e medicina do trabalho, inclusive a Campanha Nacional de Prevenção de Acidentes do Trabalho - CANPAT, o Programa de Alimentação do Trabalhador - PAT e ainda a fiscalização do cumprimento dos preceitos legais e regulamentares sobre segurança e medicina do trabalho em todo o território nacional. 
1.3.1. Compete, ainda, à Secretaria de Segurança e Saúde no Trabalho - SSST conhecer, em última instância, dos recursos voluntários ou de ofício, das decisões proferidas pelos Delegados Regionais do Trabalho, em matéria de segurança e saúde no trabalho.

1.4. A Delegacia Regional do Trabalho - DRT, nos limites de sua jurisdição, é o órgão regional competente para executar as atividades relacionadas com a segurança e medicina do trabalho, inclusive a Campanha Nacional de Prevenção dos Acidentes do Trabalho - CANPAT, o Programa de Alimentação do Trabalhador - PAT e ainda a fiscalização do cumprimento dos preceitos legais e regulamentares sobre segurança e medicina do trabalho.

1.4.1. Compete, ainda, à Delegacia Regional do Trabalho - DRT ou à Delegacia do Trabalho Marítimo - DTM, nos limites de sua jurisdição:

a) adotar medidas necessárias à fiel observância dos preceitos legais e regulamentares sobre segurança e medicina do trabalho;

b) impor as penalidades cabíveis por descumprimento dos preceitos legais e regulamentares sobre segurança e medicina do trabalho;

c) embargar obra, interditar estabelecimento, setor de serviço, canteiro de obras, frente de trabalho, locais de trabalho, máquinas e equipamentos;

d) notificar as empresas, estipulando prazos, para eliminação e/ou neutralização de insalubridade;

e) atender requisições judiciais para realização de perícias sobre segurança e medicina do trabalho nas localidades onde não houver médico do trabalho ou engenheiro de segurança do trabalho registrado no MTB.

1.5. Podem ser delegadas a outros órgãos federais, estaduais e municipais, mediante convênio autorizado pelo Ministério do Trabalho, atribuições de fiscalização e/ou 
orientação às empresas, quanto ao cumprimento dos preceitos legais e regulamentares sobre segurança e medicina do trabalho.

1.6. Para fins de aplicação das Normas Regulamentadoras - NR, considera-se:

a) empregador, a empresa individual ou coletiva ou coletiva, que, assumindo os riscos da atividade econômica, admite, assalaria e dirige a prestação pessoal de serviços. Equipara-se ao empregador os profissionais liberais, as instituições de beneficência, as associações recreativas ou outras instituições sem fins lucrativos, que admitem trabalhadores como empregados;

b) empregado, a pessoa física que presta serviços de natureza não eventual a empregador, sob a dependência deste e mediante salário;

c) empresa, o estabelecimento ou o conjunto de estabelecimentos, canteiros de obra, frente de trabalho, locais de trabalho e outras, constituindo a organização de que se utiliza o empregador para atingir seus objetivos;

d) estabelecimento, cada umas das unidades da empresa, funcionando em lugares diferentes, tais como: fábrica, refinaria, usina, escritório. Loja, oficina, depósito, laboratório;

e) setor de serviço, a menor unidade administrativa ou operacional compreendida o mesmo estabelecimento;

f) canteiro de obra, a área do trabalho fixa e temporária, onde se desenvolvem operações de apoio e execução à construção, demolição ou reparo de uma obra;

g) frente de trabalho, a área de trabalho móvel e temporária, onde se desenvolvem operações de apoio e execução à construção ou reparo de uma obra;

h) local de trabalho, a área onde são executados os trabalhos.

1.6.1 Sempre que uma ou mais empresas, tendo, embora, cada umas delas, personalidade jurídica própria, estiverem sob direção, controle ou administração de outra, constituindo grupo industrial, comercial ou de qualquer outra atividade 
econômica, serão, para efeito de aplicação das Normas Regulamentadoras - NR, solidariamente responsáveis à empresa principal e cada uma das subordinada.

1.6.2. Para efeito de aplicação das Normas Regulamentadoras - NR, a obra de engenharia, compreendendo ou não canteiro de obra ou frentes de trabalho, será considerada como um estabelecimento, a menos que se disponha, de forma diferente, em NR específica.

1.7. Cabe ao empregador:

a) cumprir e fazer cumprir as disposições legais e regulamentares sobre segurança e medicina do trabalho; (101.001-8/11).

b) elaborar ordens de serviço sobre segurança e medicina do trabalho, dando ciência aos empregados, com os seguintes objetivos: (101.002-6/11).

I - prevenir atos inseguros no desempenho do trabalho;

II - divulgar as obrigações e proibições que os empregados devam conhecer e cumprir;

III - dar conhecimento aos empregados de que serão passíveis de punição, pelo descumprimento das ordens de serviço expedidas;

IV - determinar os procedimentos que deverão ser adotados em caso de acidente do trabalho e doenças profissionais ou do trabalho;

VI - adotar medidas para eliminar ou neutralizar a insalubridade e as condições inseguras de trabalho.

c) informar aos trabalhadores: (101.003-4/11)

I - os riscos profissionais que possam originar-se nos locais de trabalho;

II - os meios para prevenir e limitar tais riscos e as medidas adotadas pela empresa; 
III - os resultados dos exames médicos e de exames complementares de diagnóstico aos quais os próprios trabalhadores forem submetidos;

IV - os resultados das avaliações ambientais realizadas nos locais de trabalho.

c) Permitir que representantes dos trabalhadores acompanhassem a fiscalização dos preceitos legais e regulamentares sobre segurança e medicina do trabalho. $(101.004-2 / 11)$

1.8. Cabe ao empregado:

a) cumprir as disposições legais e regulamentares sobre segurança e medicina do trabalho, inclusive as ordens de serviço expedidas pelo empregador;

b) usar o EPI fornecido pelo empregador;

c) submeter-se aos exames médicos previstos nas Normas Regulamentadoras $\mathrm{NR}$;

d) colaborar com a empresa na aplicação das Normas Regulamentadoras - NR.

1.8.1. Constitui ato faltoso a recusa injustificada do empregado ao cumprimento do disposto no item anterior.

1.9. O não-cumprimento das disposições legais e regulamentares sobre segurança e medicina do trabalho acarretará ao empregador a aplicação das penalidades previstas na legislação pertinente.

1.10. As dúvidas suscitadas e os casos omissos verificados na execução das Normas Regulamentadoras - NR serão decididos pela Secretaria de Segurança e Medicina do Trabalho - SSMT. 


\section{ANEXO 4}

Roteiro para avaliar os Riscos oferecidos em uma U.A.N.

- Empresa:

- Número de funcionários:

- Jornada de trabalho:

- População de estudo:

- Número de pessoas:

- Sexo:

- Faixa etária:

- Grau de escolaridade:

- Tempo de trabalho na empresa:

- Função e Número de funções que executam:

\begin{tabular}{|c|l|l|l|}
\hline FUNCIONÁRIO & SEXO & FUNÇÃO & NÚMERO DE \\
& & & $\begin{array}{c}\text { ATIVIDADES } \\
\text { EXERCIDAS }\end{array}$ \\
\hline 01 & & & \\
\hline 02 & & & \\
\hline 03 & & & \\
\hline 04 & & & \\
\hline 05 & & & \\
\hline 06 & & & \\
\hline 07 & & & \\
\hline 08 & & & \\
\hline
\end{tabular}




\begin{tabular}{|l|l|l|l|}
\hline 09 & & & \\
\hline 10 & & & \\
\hline 11 & & & \\
\hline 12 & & & \\
\hline 13 & & & \\
\hline
\end{tabular}




\section{ANEXO 5}

- Riscos Mecânicos:

\begin{tabular}{|l|l|l|}
\hline \multicolumn{1}{|c|}{ ITENS PARA OBSERVAR } & S & N \\
\hline $\begin{array}{l}\text { Os equipamentos e máquinas se encontram em perfeito estado de } \\
\text { conservação e funcionamento }\end{array}$ & \\
\hline $\begin{array}{l}\text { Os fios elétricos dos equipamentos e máquinas estão devidamente } \\
\text { encapados }\end{array}$ & \\
\hline $\begin{array}{l}\text { As instalações elétricas dos equipamentos e máquinas são } \\
\text { blindadas, não oferecendo risco de curto circuito ou de causar } \\
\text { choque aos funcionários. }\end{array}$ & \\
\hline $\begin{array}{l}\text { Os utensílios (ferramentas) estão em perfeito estado de } \\
\text { conservação adequado ao uso. }\end{array}$ & \\
\hline $\begin{array}{l}\text { O estado de conservação dos utensílios não oferece riscos ao } \\
\text { funcionamento durante o manuseio. }\end{array}$ & \\
\hline $\begin{array}{l}\text { Os equipamentos e/ou máquinas e máquinas têm manutenção } \\
\text { preventiva }\end{array}$ & & \\
\hline $\begin{array}{l}\text { Para o manuseio e corte dos alimentos é oferecido o E.P.I. } \\
\text { adequado - luvas de malha metálica. }\end{array}$ & & \\
\hline $\begin{array}{l}\text { O número de luvas de malha são suficientes para todos } \\
\text { Os funcionários que utilizam objetos cortantes. } \\
\text { para o utilizadas luvas de flanela ou feltro ou amianto para o manuseio quentes ou do forno. }\end{array}$ & & \\
\hline O deposito de gás está localizado em área externa área de & & \\
\hline
\end{tabular}


produção de alimentos.

O depósito de gás esta devidamente cercado e identificado.

A área de produção é provida de alarmes de incêndio .

A quantidade e a localização dos extintores de incêndio esta de acordo com as exigências do Corpo de Bombeiros.

A central de gás esta localizada em área externa ao prédio da unidade de alimentação. 


\section{ANEXO 6}

- Riscos biológicos:

\begin{tabular}{|l|l|l|}
\hline \multicolumn{1}{|c|}{ ITENS PARA OBSERVAR } & S & N \\
\hline $\begin{array}{l}\text { Os lixos são acondicionados de forma adequada, não ficando } \\
\text { expostos. }\end{array}$ & \\
\hline $\begin{array}{l}\text { O local destinado ao depósito de lixo é apropriado, longe de } \\
\text { instalações alimentícias. }\end{array}$ & \\
\hline $\begin{array}{l}\text { Os funcionários usam luvas e aventais apropriados para o manuseio } \\
\text { do lixo. }\end{array}$ & \\
\hline $\begin{array}{l}\text { O piso permite o escoamento de toda a água, não ficando nada } \\
\text { empossado. }\end{array}$ & & \\
\hline $\begin{array}{l}\text { Durante os horários de produção foi mantida livre de sujidades as } \\
\text { bancadas e pisos das áreas de produção. }\end{array}$ & & \\
\hline $\begin{array}{l}\text { Em caso de ferimentos, os manipuladores protegem a parte ferida } \\
\text { adequadamente permitindo assim a manipulação de alimentos. }\end{array}$ & & \\
\hline $\begin{array}{l}\text { Os funcionários que apresentam afecção na pele, infecções, } \\
\text { inflamações são afastadas da sua atividade para tratamento. }\end{array}$ & & \\
\hline
\end{tabular}




\section{ANEXO 7}

- Riscos químicos:

\begin{tabular}{|c|c|c|}
\hline ITENS PARA OBSERVAR & $\mathbf{S}$ & $\mathbf{N}$ \\
\hline $\begin{array}{l}\text { Os produtos de limpeza utilizados nos equipamentos e na área de } \\
\text { trabalho são apropriados para esta finalidade. }\end{array}$ & & \\
\hline $\begin{array}{l}\text { Todos os produtos químicos utilizados são devidamente registrados } \\
\text { pelo Ministério da Saúde. }\end{array}$ & & \\
\hline $\begin{array}{l}\text { Os funcionários que manipulam os produtos de limpeza são } \\
\text { treinados e avaliados quanto à forma correta de uso dos mesmos. }\end{array}$ & & \\
\hline $\begin{array}{l}\text { Os usos de EPI's para a manipulação dos produtos químicos são } \\
\text { adequados à atividade realizada. }\end{array}$ & & \\
\hline $\begin{array}{l}\text { Os produtos de limpeza são armazenados em local adequado, } \\
\text { destinado para esta finalidade. }\end{array}$ & & \\
\hline $\begin{array}{l}\text { Durante a operação de limpeza não ocorre liberação de vapores } \\
\text { decorrente de detergentes, desinfetantes, etc. }\end{array}$ & & \\
\hline $\begin{array}{l}\text { Durante a operação de limpeza os funcionários apresentam irritação } \\
\text { na pele, lacrimejamento dos olhos, irritação da mucosa ocular entre } \\
\text { outros sintomas. }\end{array}$ & & \\
\hline A detetização é realizada após o horário de trabalho. & & \\
\hline A área de trabalho é bem ventilada e arejada & & \\
\hline Quando a detetização é realizada, os funcionários esvaziam a área. & & \\
\hline $\begin{array}{l}\text { Após a detetização ocorre a limpeza da área, dos equipamentos, } \\
\text { utensílios e máquinas. }\end{array}$ & & \\
\hline
\end{tabular}




\section{ANEXO 8}

- Riscos toxicológicos:

\begin{tabular}{|c|c|c|}
\hline & $\mathbf{S}$ & $\mathbf{N}$ \\
\hline $\begin{array}{l}\text { Durante a produção de alimentos os funcionários apresentam } \\
\text { irritação nos olhos, nariz ou garganta. }\end{array}$ & & \\
\hline $\begin{array}{l}\text { A produção de alimentos forma fumaça constante durante o preparo } \\
\text { das refeições. }\end{array}$ & & \\
\hline Quando realizadas frituras de alimentos o óleo não produz fumaça. & & \\
\hline $\begin{array}{l}\text { A produção de fumaça das frituras ocorre durante todo o horário de } \\
\text { almoço. }\end{array}$ & & \\
\hline O óleo utilizado para fritura é trocado todos os dias & & \\
\hline As chapas são utilizadas todos os dias na preparação de grelhados & & \\
\hline Existe preparação de carnes em churrasqueiras que utilizam carvão & & \\
\hline A churrasqueira fica funcionando durante todo o horário do almoço & & \\
\hline $\begin{array}{l}\text { O óleo utilizado nas fritadeiras é utilizado para fritar alimentos } \\
\text { diversos no mesmo dia, sem a troca deste. }\end{array}$ & & \\
\hline $\begin{array}{l}\text { Existe controle de tempo e temperatura de exposição dos alimentos } \\
\text { nos fornos de convecção }\end{array}$ & & \\
\hline $\begin{array}{l}\text { Existe controle para recebimento dos alimentos in natura para } \\
\text { exclusão quando não apropriados }\end{array}$ & & \\
\hline $\begin{array}{l}\text { Existe manual disponível com critérios para recebimento de } \\
\text { alimentos }\end{array}$ & & \\
\hline
\end{tabular}




\section{ANEXO 9}

CARDÁPIO 26 A 30 DE JANEIRO DE 2004

\begin{tabular}{|c|c|c|c|c|c|}
\hline & SEGUNDA (26/01) & TERÇA (27/01) & QUARTA (28/01) & QUINTA (29/01) & SEXTA (30/01) \\
\hline $\begin{array}{l}\text { PRATO } \\
\text { PRINCI } \\
\text { PAL }\end{array}$ & $\begin{array}{l}\text { Peito de frango } \\
\text { grelhado, } \\
\text { Contrafilé grelhado } \\
\text { Carne moída com } \\
\text { batatas } \\
\text { Frango } \\
\text { passarinho } \\
\text { Lombo de porco } \\
\text { assado ao molho } \\
\text { agridoce, } \\
\text { Coração de } \\
\text { acebolado }\end{array}$ & $\begin{array}{l}\text { Coxa de frango } \\
\text { grelhado, } \\
\text { Picanha grelhada, } \\
\text { Peito de frango } \\
\text { oriental, } \\
\text { Carne de panela, } \\
\text { Bisteca grelhada, } \\
\text { Strogonof de } \\
\text { carne. }\end{array}$ & $\begin{array}{l}\text { Peito de frango } \\
\text { grelhado, } \\
\text { Contrafilé grelhado, } \\
\text { Carne de sol com } \\
\text { mandioca, } \\
\text { Lingüiça assada, } \\
\text { Moqueca de peixe, } \\
\text { Almôndega ao molho } \\
\text { sugo. }\end{array}$ & $\begin{array}{l}\text { Peito de frango } \\
\text { grelhado, } \\
\text { Picanha grelhada, } \\
\text { Kafka } \\
\text { Quibe assado - cru - } \\
\text { frita, } \\
\text { Frango ao molho } \\
\text { com quiabo, }\end{array}$ & $\begin{array}{l}\text { Peito de frango } \\
\text { grelhado, } \\
\text { Contrafilé grelhado } \\
\text { Feijoada completa } \\
\text { Coxa de frango } \\
\text { assada recheada } \\
\text { com queijo, } \\
\text { Bife a role }\end{array}$ \\
\hline $\begin{array}{l}\text { PRATO } \\
\text { VEGET } \\
\text { ARIANO }\end{array}$ & $\begin{array}{c}\text { Carne de soja } \\
\text { refogada }\end{array}$ & $\begin{array}{l}\text { Lasanha de } \\
\text { berinjela com } \\
\text { carne de soja }\end{array}$ & Bolinho de soja & Soja xadrez & Soja ao sugo \\
\hline $\begin{array}{l}\text { ACOMP } \\
\text { ANHAM } \\
\text { ENTOS }\end{array}$ & $\begin{array}{l}\text { Arroz branco } \\
\text { Arroz integral } \\
\text { Arroz com milho } \\
\text { Feijão carioca } \\
\text { Feijão preto }\end{array}$ & $\begin{array}{l}\text { Arroz branco } \\
\text { Arroz integral } \\
\text { Arroz com passas } \\
\text { Feijão carioca } \\
\text { Feijão preto }\end{array}$ & $\begin{array}{l}\text { Arroz branco } \\
\text { Arroz integral } \\
\text { Arroz a grega } \\
\text { Feijão carioca } \\
\text { Feijão preto }\end{array}$ & $\begin{array}{l}\text { Arroz branco } \\
\text { Arroz integral } \\
\text { Arroz com lentilha } \\
\text { Feijão carioca } \\
\text { Feijão preto }\end{array}$ & $\begin{array}{c}\text { Arroz branco } \\
\text { Arroz integral } \\
\text { Arroz com } \\
\text { espinafre } \\
\text { Feijão carioca } \\
\text { Feijão preto }\end{array}$ \\
\hline $\begin{array}{l}\text { GUARNI } \\
\text { ÇÕES }\end{array}$ & $\begin{array}{l}\text { Suflê de cenoura } \\
\text { Lasanha a } \\
\text { bolonhesa, } \\
\text { Espaguete ao alho } \\
\text { e óleo, }\end{array}$ & $\begin{array}{l}\text { Suflê de batatas } \\
\text { Canelone ao } \\
\text { molho sugo, } \\
\text { Talharim a } \\
\text { calabresa, }\end{array}$ & $\begin{array}{l}\text { Suflê de vagem, } \\
\text { Ravióli ao gratim, } \\
\text { Espaguete com } \\
\text { manjericão, } \\
\text { Conchilli ao molho de }\end{array}$ & $\begin{array}{l}\text { Suflê de queijo, } \\
\text { Macarrão barrolo, } \\
\text { Nhoque a milanesa, } \\
\text { Penne ao alho e } \\
\text { óleo, }\end{array}$ & $\begin{array}{l}\text { Suflê de presunto, } \\
\text { Rondelli ao molho } \\
\text { sugo, } \\
\text { Talharim a } \\
\text { bolonhesa, }\end{array}$ \\
\hline
\end{tabular}




\begin{tabular}{|c|c|c|c|c|c|}
\hline & $\begin{array}{l}\text { Penne a parisiense, } \\
\text { Berinjela a } \\
\text { milanesa, } \\
\text { Repolho } \\
\text { açafrão, } \\
\text { Farofa de cebola } \\
\text { Verduras refogadas }\end{array}$ & $\begin{array}{l}\text { Fusilli ao gratim, } \\
\text { Banana com } \\
\text { queijo e canela, } \\
\text { Bolinho de arroz, } \\
\text { Farofa de carne } \\
\text { Verduras } \\
\text { refogadas. }\end{array}$ & $\begin{array}{l}\text { salsicha, } \\
\text { Batata frita, } \\
\text { Torta madalena, } \\
\text { Cenoura no vapor, } \\
\text { Farofa de bacon, } \\
\text { Verduras refogadas. }\end{array}$ & $\begin{array}{l}\text { Empadão de frango, } \\
\text { Banana frita, } \\
\text { Tabule, } \\
\text { Pasta de grão de } \\
\text { bico e de berinjela, } \\
\text { pão sírio e esfira, } \\
\text { farofa de carne, } \\
\text { verduras refogadas. }\end{array}$ & $\begin{array}{l}\text { Fusilli com frango, } \\
\text { Torresmo, } \\
\text { Vinagrete, } \\
\text { Couve a mineira, } \\
\text { Farofa de bacon, } \\
\text { Escondidinho de } \\
\text { mandioca, } \\
\text { Verduras } \\
\text { refogadas. }\end{array}$ \\
\hline
\end{tabular}

